\title{
SÁ-CARNEIRO: VONTADE DE MORTE, SAUDADE DE VIDA*
}

\author{
Maria Elvira Brito Campos* \\ Universidade Federal do Piauí
}

Resumo: O presente trabalho contempla a elaboração da ideia de morte no poema "Dispersão" de Mário de Sá-Carneiro. A análise e interpretação pretendem oferecer uma leitura crítica dos aspectos inerentes à inquietação/obsessão do sujeito lírico frente ao tema apresentado. A delicadeza da poesia de Sá-Carneiro, em alguns momentos "preparatória para a morte", permite uma visão labiríntica, embutida, condicionada à quebra de limites, o que é exemplificado em seus poemas. Daí o cotejo da ideia de morte como perpetuação de um instante, independentemente dos resultados que essa ruptura possa revelar. Assim, trazer a lume o poema Dispersão é entendê-lo como um belo exercício de observação da circularidade, do movimento, da sinuosidade, do eterno retorno. As reticências, a luminosidade, as entradas e saídas em estados de alma controversos, tudo isso constitui a rápida duração da vida do poeta, enquanto sua poesia, como tecelãs de um puzzle que estamos sempre tentando montar, continua a nos entreter, um século após ser escrita, imortalizando o poeta que tanto se recusou a viver.

Palavras-chave: Dispersão. Sá-Carneiro. Morte.

Em suma, não creio em mim, nem no meu curso, nem no meu futuro [...]. E sofro também, meu querido amigo, por coisas mais estranhas e requintadas - pelas coisas que não foram.

Mário de Sá-Carneiro em carta a Fernando Pessoa, em 16/11/1912.

Quase toda a obra de Sá-Carneiro tem como tema a obsessão pela morte. Em seu primeiro livro de poesias, Dispersão ([1913] 1995), Sá-Carneiro reúne doze poemas e nele, o poema homônimo "Dispersão", em que a visão do "eu lírico" é voltada para dentro. Esse "dentro" revela o seu duplo, o seu "outro", o sentimento de saudade de si mesmo. As imagens saudosistas e decadentistas moldam a dramaticidade do poeta que fazia de sua vida uma obra de arte. Poema que revela grande emoção, "Dispersão" canta a recordação, o tempo, a perda de si mesmo, de sua substância, num subjetivismo que revela a ânsia pelo imediatismo, pelo

\section{Esta obra está licenciada sob uma Creative Commons - Atribuição 4.0}

\footnotetext{
* Este texto é resultado dos meus estudos no curso de Mestrado, pela Universidade de São Paulo, sob orientação da saudosa e muito querida Professora Doutora Benilde Justo Lacorte Caniato, a quem dedico.

* Professora de Literatura Portuguesa da Universidade Federal do Piauí. Pós-doutora em Literatura Portuguesa pela Universidade de Coimbra (2013). Doutora em Estudos Comparados de Literaturas de Língua Portuguesa pela Universidade de São Paulo (2003). E-mail: <mebcampos@hotmail.com>.
} 
agora. Em “Além-Tédio", que também faz parte do livro Dispersão, o sujeito lírico exprime desânimo pela vida, a vontade de deixar-se aquietado à espera da morte e da passagem dos dias. Mas o que chama a atenção é o fato de, mesmo insistindo no tema da morte, continuar produzindo avidamente, ora em tinta dourada, ora em tinta esfumada, a vida que ainda devora!

Como exemplo, seu segundo livro de poesias, Indícios de Ouro ([1914] 1995), conta com trinta e dois poemas, entre os quais, "Serradura". Nele, a ideia de morte se faz clara, revela o "fardo que maça, a vontade de endoidecer". O mesmo sentimento de abandono e ao mesmo tempo sarcástica, transparece em "Aqueloutro" ou "Fim", os quais revelam o poeta na imagem de um menino inútil e desajeitado - "Caranguejola". Contudo, continuava a escrever, ou seja, a vontade de morte não lhe cortava o fôlego, ao contrário, parecia instigar-lhe nessa busca constante e curiosa marcada pela sensação de finitude. Interessante lembrar o escritor português Lobo Antunes, em uma de suas entrevistas, ao afirmar que "escrever incessantemente é não morrer". E é isso o que percebo em Sá-Carneiro. Embora a ideia de morte seja constante, mesmo em "Fim", do livro Últimos Poemas [s.l.: s.n.], percebe-se mais acentuadamente a teatralização da morte, numa descrição afetada, quase circense, do morto que exige a desvalorização do seu velório, sob a visada da onipotência que pensa obter com a morte, impondo seus desejos aos vivos. Ou seja, ainda há o que se viver, embora tenha morrido dois meses após escrever esse poema.

Enfim, como é sabido, Mário de Sá-Carneiro suicidou-se em 26 de abril de 1916, em um quarto do Hotel de Nice, no Pigalle, com cinco frascos de arseniato de estricnina. Com uma vida foi marcada por altos e baixos depressivos, crises que se alternavam com a passagem do tempo, ele não deixou de produzir, nessas intersecções. A decisão pelo suicídio, entretanto, tinha sido tomada há muito, desde sempre; o poeta havia comunicado aos amigos o seu intento por diversas vezes. Em $\operatorname{cartas}^{1}$ a Fernando Pessoa, ele afirma:

[...] coisa interessante, quando medito horas no suicídio, o que trago disso é um doloroso pesar de ter de morrer forçosamente um dia mesmo que não me suicide. [...] É hoje, segunda-feira 3 que morro atirando-me para debaixo do Metro (ou melhor "Nord-Sud") na estação de Pigalle. [...] É agora, mais do que nunca, o momento.

Carta a Fernando Pessoa [s.d.] (provavelmente de 3 de abril de 1916).

Ou ainda:

Meu querido Amigo.

A menos de um milagre na próxima segunda-feira, 3 (ou mesmo na véspera), o seu

\footnotetext{
${ }^{1}$ Citações diversas recolhidas em cartas a Fernando Pessoa.
} 
Mário de Sá-Carneiro tomará uma forte dose de estricnina e desaparecerá deste mundo. É assim tal e qual - mas custa-me tanto a escrever esta carta pelo ridículo que sempre encontrei nas «cartas de despedida»... Não vale a pena lastimar-me, meu querido Fernando: afinal tenho o que quero: o que tanto sempre quis - e eu, em verdade, já não fazia nada por aqui... Já dera o que tinha a dar. Eu não me mato por coisa nenhuma: eu mato-me porque me coloquei pelas circunstâncias - ou melhor: fui colocado por elas, numa áurea temeridade - numa situação para a qual, a meus olhos, não há outra saída. Antes assim. É a única maneira de fazer o que devo fazer. Vivo há quinze dias uma vida como sempre sonhei: tive tudo durante eles: realizada a parte sexual, enfim, da minha obra - vivido o histerismo do seu ópio, as luas zebradas, os mosqueiros roxos da sua Ilusão. Podia ser feliz mais tempo, tudo me corre, psicologicamente, às mil maravilhas, mas não tenho dinheiro. [...]

Carta a Fernando Pessoa, datada de 31 de Março de 1916.

A contínua produção nesse curto período de vida vem a confirmar o que Edgar Morin teoriza, e que nos parece pertinente nesse caso: "com a deificação de si mesmo, nasce a angústia extrema da morte, que traz a tentação extrema da morte: o suicídio. [...] O suicídio, ruptura suprema, é a reconciliação suprema, desesperada, com o mundo (1997, p. 49) (grifos meus)". Assim, tomamos o poema "Dispersão" como ponto de chegada e ponto de partida, para o qual todos os outros convergem e do qual todos emanam, uma vez que o estado de ânimo do sujeito lírico parece se manter inalterável ao longo de suas obras. Ou seja, os poemas escritos pós "Dispersão" apresentam-se como uma reedição do tema morte.

Sobre a obsessão por esse tema, Laplanche e Pontalis (1970, p. 535) nos traz a ideia pulsão do sujeito lírico. Assim,

[...] o que Freud procura explicitamente destacar pela expressão "pulsão de morte" é o que há de mais fundamental na noção de pulsão, o retorno a um estado anterior e, em última análise, o retorno ao repouso absoluto do anorgânico. [...] É assim que em Para além do Princípio de Prazer, como o título por si mesmo indica, a pulsão de morte é postulada a partir de factos que se supõem pôr em xeque o dito princípio, mas ao mesmo tempo Freud pode concluir afirmando que "o princípio de prazer parece estar de fato ao serviço das pulsões de morte.

Mesmo tangenciando superficialmente estudos psicanalíticos, a citação acima somente tenta demonstrar que o pensamento na morte pode ter também sua vertente prazerosa. Seu encanto. A fantasia a respeito do que a morte pode representar para o outro, dor ou indignação, ao mesmo tempo em que, ao morto, pode representar o alívio em deixar o sofrimento humano: isso pode parecer agressivo aos olhos de alguns, mas essa mesma fantasia, certamente, passa pelo imaginário coletivo. O que o sujeito lírico faz é ensaiar esse instante de fantasia. E revelar o seu desejo.

Assim, Dispersão revela o subjetivismo decadentista - a constante busca do subjetivismo decadentista - o que também caracteriza a prisão do mito no labirinto. O poema homônimo revela a experiência dos limites do espaço infinito: morte - dispersão como totalidade. Escrito em primeira pessoa, em versos heptassílabos, com rimas, ora interpoladas, 
ora cruzadas, o poema possui vinte e três estrofes. A alternância da rima e a nasalidade em alguns versos possibilita vislumbrar a imagem labiríntica, o que sugere o aprisionamento interior. O sujeito lírico interioriza-se, internaliza-se, cindindo-se. Torna-se dois em um, que se desconhecem mutuamente. E advém daí a necessidade ou o desejo ambíguo de buscar-se, embora sabendo-se perdido completamente. O sujeito, como um "ser-labirinto", não possui o "fio de Ariadne" que o faça encontrar a saída, como se pode observar na primeira estrofe, base estrutural e chave para a compreensão do poema (grifo meu):

\footnotetext{
Perdi-me dentro de mim (v. 1)

Porque eu era labirinto, (v. 2)

E hoje quando me sinto, (v. 3)

É com saudades de mim. (v. 4)
}

O verso inicial revela a temática do poema. O "eu lírico" viaja em si mesmo e em seu duplo, em digressões temporais e espaciais, revendo situações e sentimentos. O tom lamentoso, expresso pela sonoridade das rimas em /im/, revela ao leitor o ânimo da enunciação poética. Utilizando pretérito perfeito (perdi), que indica ação conclusa, e o pretérito imperfeito (era), que indica uma ação inconclusa, o "eu lírico" continua no presente (sinto). Daí a contradição: há um tempo para não se deixar perder, mas uma vez que se foi abandonado no labirinto, perde-se definitivamente, por não saber ou não querer encontrar a saída no tempo atual.

Em carta a Fernando Pessoa, Sá-Carneiro acentua, a respeito desse poema, um certo caráter autobiográfico: "Depois de composta a poesia, vi que ela era sincera, que encerra talvez um canto do meu estado de alma. Pelo menos, creio-o". (Cartas, v. I, p. 109-111). Essa sinceridade confessa do autor impõe, todavia, a consciência do duplo, no sujeito lírico, determinando a perda de uma parte de si mesmo, já antecipada pelo verso quatro, quando se refere a "saudades de mim", que se espalha no poema, como nos versos que seguem:

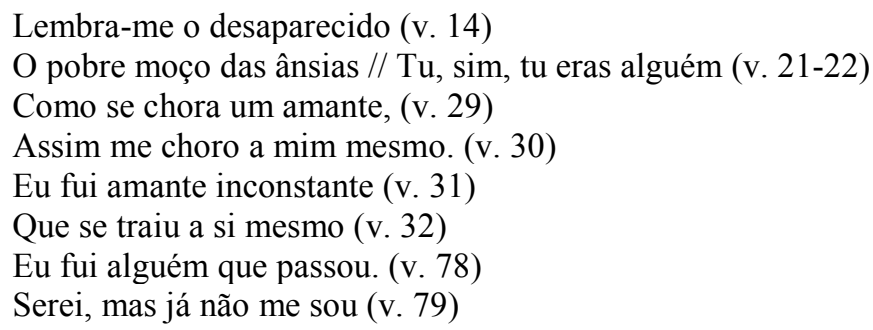

A ideia do perder-se e do achar-se revela a ansiedade em sair do claustro, mas a saída, entretanto, é a porta de entrada no poema: a ideia de morte. O sujeito lírico continua a peregrinação em busca de sentido, de identidade, de sensações embutidas. A relação temporal é feita numa linha de tempo definida: trata-se da caminhada para o fim, relatada em tempo 
pretérito, num passado que se arrasta. A reflexão paira em torno do tempo perdido, tempo de vida decorrido em busca de algo que, para o sujeito lírico, parece inatingível: satisfação em viver - a busca dos prazeres, a observação do cotidiano e da felicidade alheia. Caracteriza-se como ser-já-passado, que existiu, por isso determinado pela atemporalidade: "O tempo que aos outros foge / Cai sobre mim feito ontem". (vv. 11-12)

A observação da rotina externa não lhe faz nenhum sentido, como "O Domingo de Paris", em que relaciona a mesmice familiar em contraposição ao traço poético: "E os que olham a beleza / Não têm bem-estar nem família" (vv. 19-20): nesse, o encontro com a liberdade.

Reflete sobre o "ser" que foi, traduzindo-se como "pobre moço das ânsias", o sonhador (a grande ave dourada), que visava voar cada vez mais alto, ao mesmo tempo que se enfadava "Mas fechou-as saciada / ao ver que ganhava os céus", na incapacidade de amar-se e, na impossibilidade de receber e buscar amor, agindo como um amante inconstante, "traidor de si mesmo".

E o presente? Como se apresenta? A atemporalidade o remete à falta de espaço: "Não sinto o espaço que encerro" (v. 33). Sem espelho, não se pode ver no seu projeto, vocábulo carregado de sugestividade: nem se projeta no espelho (deixa de ser visível, enquanto imagem) nem na atividade. A rotina interna é reveladora do desânimo e da apatia.

O sujeito lírico reconhece o seu duplo perdido: sua alma que morreu antes do corpo. A estrofe 10 marca, então, o segundo movimento do poema:

\footnotetext{
Regresso dentro de mim (v. 37)

Mas nada me fala, nada! (v. 38)

Tenho a alma amortalhada, (v. 39)

Sequinha, dentro de mim. (v. 40)
}

Justifica a sua ausência e o sofrimento da perda, considerando-a involuntária, na estrofe 11:

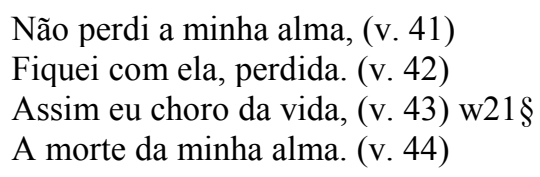

Esclarece as razões de sua solidão, personificando a alma, a falta que lhe faz "gentil companheira", que se manteve invisível, mas presente no homem que passou, descrevendo-a com a "boca doirada", "corpo esmaecido", "hálito perdido". Uma alma-mulher não tão bela, porém habitual: "Que vem da tarde doirada" (v. 52).

Solitário, saudoso, des-almado, surge o sentimento/desejo de morte/“dispersão total”, 
única saída possível para o sujeito lírico. E a deseja "lá longe", em outra capital - ao norte... A morte é vista como algo fantástico, com certo tom melancólico, mas sem drama ou dor: rolos de fumo, azul-de-agonia, em sombra, sumindo, no além, desaparecendo, como fumaça.

E manifesta a saudade de si mesmo, principalmente das mãos brancas, "Tristes mãos longas e lindas", que não foram tocadas e nem aprenderam a tocar, viveram sem sentido. Autoapieda-se, determinando o terceiro movimento do poema, carregado de dramaticidade, como se vê na estrofe 19:

\author{
E tenho pena de mim, (v. 73) \\ Pobre menino ideal... (v. 74) \\ Que me faltou afinal? (v. 75) \\ Um elo? Um rastro?... Ai de mim!... (v. 76)
}

E expressa a conformação diante da morte, diante da realidade que consegue absorver. Alma crepuscular, "alguém que já passou", porque se perdeu no jovem ansioso de um tempo passado, vivenciador de grandes sonhos e ideais, entorpecido pelo álcool, pela ausência de ânimo, com a alma perdida, dormente, o sujeito lírico conclui no último movimento do poema, ilustrado na estrofe 22:

Perdi a morte e a vida (v. 85)
E, louco, não enlouqueço... (v. 86)
A hora foge vivida, (v. 87)
Eu sigo-a, mas permaneço. (v. 88 )

Perdendo-se definitivamente no labirinto, o sujeito lírico acentua em desespero final, na elaboração do último quarteto, que não possui o primeiro e quarto versos, sugerindo um dístico. Na verdade, pode-se inferir como a expressividade do devaneio poético também vai morrendo, o que está configurado nos sonhos em transcendência, sugeridos pelas expressões, "castelos desmantelados" (sonhos desfeitos), em referência a "fazer castelos no ar". Essa atitude é inerente aos que projetam ideais e "leões alados sem juba", presos à terra, mas alados (podem voar), porém sem beleza (sem juba, o que dá sentido à beleza do animal, "rei da selva"). A estrofe, também "desmantelada", pode sugerir a última divagação, ou o último pensamento (se é que é possível pensar), aos que sucumbem à morte, o que pode também ser comprovado pela rima interna: desmantelados/alados.

O sujeito lírico, em resumo, pela leitura que se pode fazer do poema, embora não a única, estabelece nele os pontos essenciais que caracterizam uma atitude poética: desinteresse pela vida, desejo de transcendência, tendo a morte como instigação fundamental à atividade literária.

O poema é iniciado pela bilabial oclusiva [p] (Perdi-me...), o que pode corresponder 
à porta: entrada para o labirinto. A emissão da consoante expressa determinação, clareza para narrar o devaneio. O verso inicial afirma e justifica o fulcro do poema, que é quase uma narrativa do caminhar pelos compartimentos do labirinto. A ideia de morte pode ser o enigma a que o sujeito lírico vai ao encontro. Morte enquanto realização, satisfação, calmaria. As portas do labirinto constituem a relação temporal estabelecida pelo "eu" lírico: ontem, hoje, amanhã. Elas se desdobram e se multiplicam, à medida que o "eu" faz suas observações e digressões.

Nesse poema, no entanto, o Minotauro pode se constituir na aquietação, na paz procurada, no desejo de que a morte pode estar na dispersão total e que, no momento, é somente um desejo impossibilitado de se concretizar.

A repetição de vocábulos é uma constante no poema que, embora mantendo a sonoridade rímica, pela repetição exata dos vocábulos, como rima idêntica, se configura como uma ressonância advinda da repetição, como um eco que se faz ouvir após a emissão de uma voz enunciada no abismo, ou no recôndito do labirinto. A palavra bate e volta, como som que retorna após sua emissão. O eco se faz sentir também no plano do conteúdo (o que diz) e não só no plano de expressão (como se manifesta), pois o sujeito lírico parece perdido nos compartimentos do labirinto. Interessante notar que há momentos em que o sujeito lírico parece encontrar a solução, quando produz suas reflexões, no sentido de compreender o que o incomoda. A forma contempla este aspecto.

Ao se fazer um levantamento das rimas em eco, pode-se observar que elas não aparecem da mesma forma. Há um trabalho artesanal na construção dos versos que parece sugerir o percurso labiríntico do sujeito lírico pelo interior de si mesmo, considerando que às vezes se apresenta certa possibilidade de abertura ou fechamento, isto é, a sensação de estarse preso num labirinto e saber-se caminhando para a saída, outras vezes, de sentir-se totalmente perdido e ter que recomeçar. Dessa forma, o que pode parecer uma atitude lúdica, de repente vai-se constituindo em algo dramático, definindo a impotência humana diante do próprio desejo. É o que parece ser a proposta do poema que, aos poucos, vai-se encaminhando cada vez mais para o seu tema instigante, a pulsão de morte, o encontro com Thánatos, ou, mais precisamente, ao desejo de morte, latente no sujeito lírico.

A partir disso, visualizamos a distribuição das rimas nos primeiros poemas:

- Nas seis primeiras estrofes, o eco se mantém no primeiro e quarto versos: 
- Mim / labirinto / sinto / mim, vida / sonhar / ultrapassar / vida, ontem / hoje / foge / ontem, Paris / desaparecido / comovido / Paris, família / singeleza / beleza / família;

- Na sétima, oitava e nona estrofes, no segundo e quarto versos:

- Dourada / céus / saciada / céus, amante / mesmo / inconstante / mesmo, encerro / projeto / erro / projeto;

- Nas estrofes dez, onze, doze e treze, volta a ecoar no primeiro e quarto versos:

- Mim / nada / amortalhada / mim, alma / perdida / vida / alma, recordo / companheira / inteira / recordo, doirada / esmaecido / perdido / doirada;

- Na estrofe 14, no primeiro e terceiro versos:

○ Saudades / enlacei / saudades / sonhei;

- Nas estrofes 15 e 16, apresenta rimas normais alteradas:

- ABAB: morte / total / norte / capital e dia / fumo / agonia / sumo;

- Na estrofe 17, o eco retorna no segundo e quarto versos:

- Saudade / brancas / piedade / brancas;

- Nas estrofes $18,19,20$ e 21 , volta para o primeiro e quarto versos:

- Lindas / dar / apertar / lindas, mim / ideal / afinal / mim, crepúsculo / passou / sou / crepúsculo, outonal / vagamente / dormente / outonal;

- A estrofe 22, sem eco, apresenta novamente rimas alternadas:

- ABAB: vida / enlouqueço / vivida / permaneço

- A última estrofe apresenta rima interna e fecha o poema, guardando o sujeito lírico no interior do labirinto:

Castelos desmantelados, (v. 89)

Leões alados sem juba... (v. 90)

Referindo-se à deusa Eco, Françoise Graziani (1997, p. 292) afirma que ela é a reveladora das verdades ocultas sob aparências enganosas. Eco aparece como o próprio signo 
da palavra divina, que só pode se revelar por meio de enigmas. Assim sendo, ela age como mediadora entre a alma humana e o divino. A natureza simbólica dessa palavra está contida justamente no fato de que ela "não é senão voz", que condensa numa única palavra todo um discurso que não lhe é permitido. Aproveitando a ideia de eco para alegorizá-la como reedição, reverberação, e Françoise Graziani (1997, p. 292) arremata: “[Eco] vive na medida em que falas. [... ] Há um só que vive e dois que falam. [...] Ela é um outro em tu mesmo. [...] Se morres, ela morre."”.

Assim, em "Dispersão", nos versos em que há uma rima formal, percebe-se uma breve alteração à dispersão propriamente dita, pois ela compreende um momento de devaneio, momento fugaz, passageiro. Quando há alteração, percebe-se uma quebra nesse devaneio, para formalização da rima, que é um ato pensado, medido, formal, implicando razão ou volta da racionalidade, caracterizando o momento de lucidez. Breve momento de lucidez como se, por um momento, o sujeito lírico encontrasse a saída. Nesses momentos, ele descreve o cenário da morte, as expectativas do que sua morte pode causar nas pessoas, a reação dos outros. Faz, ainda, uma rápida parada no devaneio, conferindo um tempo dentro do momento fugidio. $\mathrm{Na}$ estrofe final, os versos intercalam-se entre pensamentos, quando o "eu lírico" percebe a impossibilidade momentânea de concretizar seu desejo, de encontrar o seu Minotauro. O devaneio, entretanto, continua em outros poemas.

Como visto, em seus momentos mais sofridos, o eu-lírico fica inerte, e preso ao devaneio pessimista, dando voz à alma. Quando se dá o contrário, a voz é do corpo. A mais intensa solidão é da alma, pois o corpo participa do social, mesmo que se esforçando, está presente nos cafés de Paris, nas tertúlias, nos salões. A alma, por sua vez, reflete a solidão poética. O que a alma exige, o corpo não dá. $\mathrm{O}$ corpo repete o ritual comum, a alma anseia por mais. Se pudesse conciliar corpo e alma, talvez o conflito se solucionasse. Cindido, o sujeito lírico vai ruminando sua melancolia e angústia de viver entre momentos contrapostos que se caracterizam entre a oposição temporal, a oposição espacial, momentos de sobriedade e embriaguez, oferecendo uma lírica sofrida, dolorida, que parece sugerir certo distanciamento da atitude que assumiu a tendência simbolista: a necessidade de transcender-se e a resistência material, física. Sá-Carneiro se nos apresenta como um poeta do Orpheu, mas a sua rebeldia tem origens mais contundentes que firmadas pelas vanguardas daquele momento. Talvez venha daí a extrema angústia e melancolia retratadas na sua produção poética.

Finalmente, voltando ao mote lançado sobre a estrutura labiríntica do poema, quanto à forma e ao conteúdo, esta descreve a introjeção ou o mergulho do sujeito lírico em si 
mesmo. A partir da décima estrofe, o "eu-lírico" descreve o seu retorno, o seu regresso, e esse regresso resgata uma série de sentimentos e recordações do outro, do que vê, do que assiste à cena. Do que assiste à morte em vida, a que é experienciada pelo seu duplo, a partir da sua revelação, na oitava estrofe. Com essa revelação, ocorre a desmaterialização do sujeito lírico, que se dilui até o regresso do outro, do que procura seu objeto perdido, que ele próprio não consegue tocar. Um é o ser desamparado, o outro é o ser que experiencia.

\section{Referências}

BRUNEL, Pierre (Org.). Dicionário de Mitos Literários. Rio de Janeiro: José Olympio, 1997.

LAPLANCHE, J.; PONTALIS, J. B. Vocabulário de Psicanálise. 5.ed. São Paulo: Martins Fontes, 1970.

MOISÉS, Massaud. Dicionário de Termos Literários. São Paulo: Cultrix, 1974.

MORIN, Edgar. O homem e a morte. Lisboa: Biblioteca Universitária, 1997.

SÁ-CARNEIRO, Mário. Obra completa. Introdução e organização de Alexei Bueno. Rio de Janeiro: Nova Aguilar, 1995.

. Poesia. Fernando Paixão (Org.). São Paulo: Iluminuras, 1995.

[Recebido em 11 de agosto de 2016 e aceito para publicação em 22 de agosto de 2016]

\section{Sá-Carneiro: will to death, life miss}

Abstract: This paper considers the elaboration of the idea of death in Mário de Sá-Carneiro's poem "Dispersão". The analysis and interpretation intend to offer a critical reading of the lyrical subject's restlessness /obsession aspects facing the thoughts of death. The gentleness of Sá-Carneiro's poetry, at times "preparatory to death", allows a labyrinthine, embedded, conditioned vision on breaking boundaries, which is exemplified in his poems. Hence collating of the idea of death as a perpetuation of an instant regardless of the outcomes that such breakage might reveal. Thereby, bringing to light the poem "Dispersão" means to understand it as a fine exercise of observing the circularity, the motion, the sinuosity, the eternal return. The ellipses, the brightness, the entrances and exits on controversial moods, all of this constitutes the short duration of the poet life, while his poetry, like weavers of a tapestry that we are always trying to put threads together, continues to entertain us, a century after be written, immortalizing the poet who copiously refused to live.

Keywords: Dispersão. Sá-Carneiro. Death.

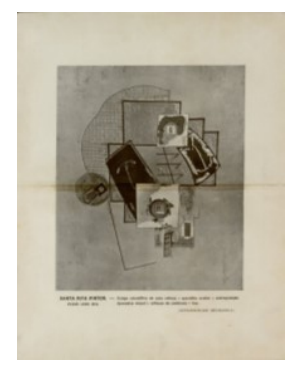

